\title{
Research on the development and inheritance of local folk sports in the construction of New Countryside
}

\author{
Wu Wen ${ }^{1 \mathrm{a}}$ Ying $\mathrm{Li}^{2 \mathrm{~b}}$ \\ 1,2 Pingxiang University, Jiangxi 337055, China \\ a2633241463@qq.com, b359020645@qq.com
}

Key words: new countryside; folk sports; development; inheritance

\begin{abstract}
: the broad masses of peasants to meet the growing spiritual and cultural needs of the important content of new rural construction, the local folk sports as rooted in the Chinese culture sports, rich in content, low cost, easy to accept, it become to solve the problem of rural cultural construction is the most suitable choice, therefore, it is necessary to folk sports to the majority the rural population fitness leisure activities, make it play a greater role in the construction of new countryside.

In recent years, the country to accelerate the construction of new socialist countryside, a specific plan for building a "new socialist countryside" strategy, which clearly put forward: "to promote the implementation of farmers fitness project, actively carry out various forms of popular sports activities, edutainment, local and national characteristics of protection and the development of excellent traditional culture, meet the farmers' level, many aspects of the spiritual and cultural needs." local folk sports and rooted in the masses, with a deep foundation of the masses, by rural residents love, for rural areas to carry out various forms of mass cultural activities play a good role. Therefore, the fundamental way in the new rural construction in the development of folk sports and use of resources is the solution to the development of rural sports practice, and is rich in rural people Spiritual and cultural life, to achieve the harmonious development of the new rural cultural atmosphere, the realization of the grand blueprint of socialist modernization.
\end{abstract}

\section{The significance of the development and inheritance of folk sports in local area}

\subsection{To carry out the folk sports project is conducive to its inheritance and development}

China is a multi-ethnic country, formed a very rich folk sports resources in the long history of farming culture. But with the acceleration of social development and the development of globalization, the development of folk sports Chinese space more and more small, forced to gradually marginalized or even loss and fault, become a sports research "fossil. Rooted in the rural folk sports has practicability, simplicity, nationality, entertainment and other unique features. So, to carry out a wide range of folk sports in rural sports development has important theoretical significance to the inheritance and development of folk sports.

1.2 Greatly promoted the coordinated development of rural sports and the construction of new rural areas

To carry out the folk sports activities in rural areas, farmers can not only promote the improvement of health, but also can enrich the rural culture, to promote inter ethnic communication, is conducive to the establishment of a healthy and reasonable life style, to create a civilized, harmonious environment in rural areas. In recent years, the relevant policies and regulations promulgated by the State Party and the support of sports development in rural areas, the folk sports development has the advantage of favorable factors in rural areas, increase the number of rural sports population, promote the development of rural sports, ultimately achieve fitness goals, to speed up the process of new rural construction. 


\section{General situation of rural sports development}

\subsection{Current situation of the development of rural sports \\ 2.1.1 Rural sports development lags behind}

According to the State Sports General Administration "in 2007 China of urban and rural residents to participate in the survey bulletin" the current situation of physical exercise shows that in 2007 the national 16 years old and above in the urban and rural residents reached "the number of regular exercise" standard ratio of $8.3 \%$, which is $13.1 \%$ of urban residents, rural residents and the number of 4.1\%. reached the standard of Jiangxi Province, 16 years old and above urban and rural residents in $7.2 \%$, the urban residents often exercise a population of $13.1 \%$, rural residents often exercise population for $3.0 \%$. from the data analysis, Jiangxi province population and the regular exercise are still relatively large gap, especially in rural residents often exercise population. In fact, the development of rural sports in our province is still relatively backward. We should according to the situation of Jiangxi Province, the timely adjustment of the rural sports development strategy layout and focus, to further strengthen the development of rural sports.

\subsubsection{Physical exercise population of urban and rural gap is significant}

Can be seen from the above data: The city residents was much higher than that of rural residents in Jiangxi province, the gap is significant. Therefore, in the future development of mass sports in Jiangxi Province, to adjust the development strategy and focus, should put more funds, material resources, financial resources and other resources to invest in the development of rural sports, to improve two structures in urban and rural areas in the development of sports.

\subsubsection{The lack of rural sports instructors and the quality is not high}

The development of sports cannot do without people, especially the professional talents. Social sports instructors as the development of sports professionals, is a key force in the development of mass sports, mass sports is the organizer, leader, communicator, decides the quality of the development of mass sports, an important part of sports in our country. It is to promote the masses sports further social, scientific, industrial, plays a very important role in the legal system. Rural sports as an important part of mass sports, but also the development of mass sports in the most backward links, need more social sports instructors of the organization, guidance and communication. But the development is relatively backward in Jiangxi Province in mass sports. Social sports instructors can not meet the demand of the residents' physical exercise. The fact that social sports instructors in rural areas are small in quantity and the quality is not high, to open rural sports Therefore, our province should increase the training of sports instructors, improve the proportion of the dispatch of sports instructors in rural areas.

\subsection{Problems in the development of rural sports}

\subsubsection{Inadequate funding, inadequate facilities, lack of physical education professionals}

The statistics from the existing research: sports funding, venues, equipment and facilities, shortage of sports talent is the main factors restricting the development of rural sports in China. Too little investment in rural sports funds in our province and the ratio is too low, too dependent on government funding and social donation funds have become a bottleneck restricting the rural sports the development of Hunan province.

\subsubsection{Government lack of rural sports organization and management}

China has issued a number of laws and regulations on rural sports development in the new rural construction, a series of preferential policies, the development of rural sports in Jiangxi province has been greatly improved, some rural village committee established a basketball court, table tennis and activity center. But these facilities are only the government to performance, in order to an image project to cope with the higher examination. Most of the basketball court in a deserted state of neglect, some people will not use it to exercise, the existing facilities can not be fully utilized.

\subsubsection{Rural sports demand and sports to carry out the project contradiction}

In the current construction of new rural background, the national increase of rural sports support, but at the time of the assessment is to sports as the evaluation index, ignoring the advantages and the role of local folk sports. Folk sports in rural areas has the advantage of being richly endowed by 
nature, loved by the masses of peasants, just to meet the farmers' appetite a lot of folk sports, without any requirements for equipment, as long as a piece of land can, while rural areas everywhere. But with much land and few people, lots of folk sports fun, fitness effect is not less than the western sports, it can be very good for rural areas due to economic backwardness and can not carry out the defect of sports.

\section{The development principles of rural local folk sports in Jiangxi Province}

\subsection{Principles of Science}

Folk sports is rooted in the traditional culture of the Chinese nation, is the farmers created in the life practice, project and religion, most of the military, worship, festivals and other activities, which makes the folk sports some feudal superstition into negative points with more or less. Therefore, the development of folk sports in rural sports should be from the actual the development of the spirit of rigorous, serious, serious scientific attitude, select suitable for the needs of local rural masses fitness of folk sports, and proper reform, stimulate farmers to actively participate in the awareness and action.

\subsection{The principle of the farmers}

To carry out the folk sports should proceed from reality, to the health of farmers for the farmers, to the Customs for the farmers, with interest as this, to the farmers' cultural background for this, focus on the development of the broad masses of the people loved, simple, good body-building effect and in accordance with the development of modern society, the requirements of the project. Let the farmers take the initiative to participate in sports activities.

\subsection{Flexible use, according to local conditions}

Jiangxi province has a vast territory, a number of minority populations in different regions have different cultural characteristics and regional differences. The peasants as a relatively stable life groups, regional characteristics are more obvious, different villages can develop the folk sports resources are also very different. So we must develop different development plans and strategies depending on the actual situation in the development process in the development of folk sports, at the same time to make full use of local advantages and characteristics.

\subsection{Principles of economic efficiency}

In rural areas is to carry out the folk sports and not to carry out one of the important factors of western sports, folk sports is the development costs than the western sports development cost a lot. So in the development of folk sports should use conditions and the advantages of local resources, make full use of existing resources and facilities, more self-control and less transformation buy. In the actual operation process of folk sports development as far as possible investment and expenses to a minimum, and the creative development of more folk sports, make full use of social resources and the sharing of human resources, improve the development rate.

\subsection{Protection of the first principle}

The purpose of development is to protect the folk sports culture resources, namely the skill development of the folk sports is not simply the development of folk sports, while ignoring its cultural background. The folk sports culture resources are non renewable resources, once destroyed it is difficult to be restored, so adhering to the "protection first" the principle of the development of folk sports culture resources, to ensure the development of the folk sports resources "authentic". Therefore, the development of folk sports in rural areas must adhere to the protection of the first principle, protection first, development, development of edge edge protection.

\section{Folk sports development and inheritance measures}

\subsection{Government organizations play a leading role}

We should recognize the importance of folk sports, folk sports should be given position. We must be fully aware of the important historical significance and practical significance of folk sports, to the outstanding cultural heritage inheritance of folk sports of the Chinese nation, given the status of folk sports. The development direction should be followed by government policies or measures 
to guide the folk sports the development of folk sports. Once again the government should intensify the folk sports public infrastructure investment, including manpower, material resources, financial resources and other aspects, to strengthen the development of folk sports resources, mining of the excellent folk sports should strengthen the protection, management and utilization.

\subsection{People play the main role of inheritance}

First of all, to the heritage of people provide skills to play arena, and give the inheritance of certain political and economic benefits. Secondly, the organization inheritors of some learning and training, enhance the heritage of people a sense of responsibility and stimulate the inheritance of human creativity, make these folk art, keep pace with the times, create more and better works. Thirdly, funding and to encourage people to participate in various kinds of folk heritage of the games, games, technical exchanges, and all over the country folk heritage experts, exchange of technology, at the same time, play colleges and universities, scientific research institutions in the scientific research, the advantages of personnel training, to provide theoretical support for the folk sports.

\subsection{Schools to play the role of educational heritage}

School education is one of the important channels of the folk sports heritage, is the main way for people to obtain fitness and fitness methods. Therefore, the introduction of folk sports class, learn from the successful development of folk sports curriculum resources in other parts of the model, realize the interaction with the research theory of folk sports in primary and secondary schools, and explore the innovation of folk sports resources, strengthen the organic combination of folk sports and other sports, is conducive to the development of folk sports curriculum, promote the development of school sports.

\subsection{Academic circle to play the role of scientific guidance}

Folk sports is a part of the folk culture, which belongs to the fine arsenic wealth of the nation, with the development of the times, preservation of folk sports is a pressing matter of the moment the protection and development of traditional culture. The folk sports cultural heritage database should be established, and online publishing, make the information resources quickly convert the valuable information to stimulate people pay attention to the folk sports cultural activities and participation passion, is conducive to the permanent preservation of folk sports cultural heritage of all kinds of text data and video data, is conducive to physical education, scientific research, training and management staff to quickly access to documents, a comprehensive grasp of information. Take the traditional and modern technology combine to achieve scientific and the comprehensive protection work.

\subsection{Media to play the role of publicity}

The rapid development of information technology, social media has become an important part of people's life, the media is an indispensable factor to promote the development of things, society can through television, radio, Internet and other forms of media, publicity of folk sports.

\section{Acknowledgments:}

Draft date: $2016-10-1$

Fund project: jiangxi province sports bureau scientific research subject 《The development of new rural construction under the local folk sports and study》, number: 2016035

\section{Reference}

[1] Jia-xin Zhu.sports development in new period and empirical research [M]. Anhui: Anhui University press, 2007

[2] Chun-guang Li. The innovation and development of folk sports culture in the perspective of new rural construction [J]. business era, 2010 (15)

[3] Min Fan. Study on the development of cultural resources of Chinese folk sports [J]. sports world, 2009 (11)

[4] Yi Yuan. Research on the development strategy of rural sports in the construction of new rural 
areas in Hunan province [J]. sports science and technology literature bulletin, 2009 (5)

[5] You-jin Ouyang. Interactive research on the construction of national traditional sports and new socialist countryside[J]. Journal of Shanxi Normal University, 2008 (6)

[6] Yan-ru Li. Chinese folk sports culture resources and the development of the [J]. sports culture Herald, 2007 (7) 